Revista Brasileira de Agricultura Irrigada v.6, $\mathrm{n}^{\circ}$. 1, p 3-7 , 2012

ISSN 1982-7679 (On-line)

Fortaleza, CE, INOVAGRI - http://www.inovagri.org.br

Protocolo 070/11 - 09/11/2011 Aprovado em 19/03/2012

\title{
ESTUDO DAS PRECIPITAÇÕES MÁXIMAS PARA O MUNICIPIO DE MOSSORÓ-RN, BRASIL
}

Francisco Gilliard Chaves Freire ${ }^{1}$; Andler Milton de Paiva Oliveira ${ }^{2}$; José Espínola Sobrinho ${ }^{3}$; Rafael Oliveira Batista ${ }^{3}$; Wesley de Oliveira Santos ${ }^{2}$; Herlon Bruno Ferreira Barreto ${ }^{2}$

\section{Resumo}

O estudo das variáveis climatológicas é de grande relevância para o desenvolvimento da vida humana e muito necessário para o desenvolvimento da agricultura irrigada. O objetivo desse trabalho é determinar as precipitações máximas para diferentes períodos de retorno (2, 5, 10, 20, 50 e 100 anos) através da distribuição de Gumbel, para o município de Mossoró no Rio Grande do Norte. Para se encontrar os parâmetros de Gumbel foi utilizado o método dos momentos. Os resultados obtidos com o tempo de retorno de 2, 5, 10, 20, 50 e 100 anos foram respectivamente 46,$57 ; 115,43 ; 161,03 ; 204,76 ; 261,36$ e $303,78 \mathrm{~mm}$, respectivamente. Os resultados encontrados foram bastante significativos e muito úteis para o desenvolvimento da agricultura irrigada do Estado do Rio Grande do Norte.

Palavras - chave: Probabilidade do evento, Método dos momentos, Atividade agrícola

\section{STUDY FOR MAXIMUM RAINFALL ON MUNICIPALITY OF MOSSORÓ- RN, BRAZIL}

\begin{abstract}
The study of climatic variables is of paramount importance for the development of human life and much needed for the development of irrigated agriculture. The aim of this study is to determine the maximum rainfall for different return periods $(2,5,10,20,50$ and 100 years) through the Gumbel distribution, in municipality of Mossoró-RN, Brazil. To find the parameters of Gumbel has used the method of moments. The results obtained with the turnaround time of 2, 5, 10, 20, 50 and 100 years were 46.57, 115.43, 161.03, 204.76, 261.36 and $303.78 \mathrm{~mm}$, respectively. The results were quite significant and very useful for the development of irrigated agriculture in the state of Rio Grande do Norte.
\end{abstract}

Keywords: Probability, Moments method, Agricultural activity.

\footnotetext{
${ }^{1}$ Tecnólogo em Recursos Hídricos / Irrigação, Mestrando em Irrigação e Drenagem, bolsista da CAPES, Depto de Ciências Ambientais e Tecnológicas, UFERSA, Caixa Postal 137, CEP 59625 - 900, Mossoró, RN. Fone (88) 9714 2358. e-mail: gilliardchaves@yahoo.com.br

2 Mestrando em Irrigação e Drenagem, UFERSA, Mossoró, RN;

3 Doutor, Professor do mestrado de Irrigação e Drenagem, Depto de Ciências Ambientais e Tecnológicas,da UFERSA, Mossoró, RN
} 


\section{INTRODUÇÃO}

$\mathrm{O}$ estudo das distribuições de variáveis climáticas, como um meio de compreender os fenômenos meteorológicos, determinando seus padrões de ocorrência e permitindo uma previsibilidade do comportamento climático de uma região é uma ferramenta para o planejamento e gestão de inúmeras atividades agropecuárias e humanas (SANTOS, 2010).

Dentre os elementos do clima, a precipitação é o que mais influencia a produtividade agrícola (ORTOLANI, \& CAMARGO, 1987), principalmente nas regiões tropicais, onde o regime de chuvas é caracterizado por eventos de curta duração e alta intensidade (SANTANA et al., 2007). A oferta versus demanda de água tem exigido cada vez mais o aprimoramento de previsões de precipitação pluviométrica, para o seu uso em modelos hidrológicos em escala intrasazonal. Em regiões semiáridas a disponibilidade da previsão de precipitação na escala da bacia hidrográfica, é crucial para o operador do sistema (reservatório) tomar suas decisões (ALVES et al., 2008).

O conhecimento da frequência de ocorrência de chuvas intensas é importante porque a precipitação pluviométrica atua sobre a erosão do solo, causa inundações em áreas rurais e urbanas, condiciona projetos de obras hidráulicas, notavelmente de sistemas de drenagem, dentre muitas outras implicações. Como as séries de dados de precipitação são frequentemente, mais longas do que as de vazão, o estudo das precipitações máximas é uma das maneiras para se obter o conhecimento da vazão de enchente de uma bacia hidrográfica (TUCCI, 2000).

Historicamente a região Nordeste sempre foi afetada por grandes secas ou grandes cheias. Relatos de secas na região podem ser encontrados desde o século XVII. Estatisticamente, acontecem de 18 a 20 anos de seca a cada 100 anos (MARENGO et al., 2007). A região Norte do Nordeste do Brasil, climatologicamente apresenta o seu período chuvoso centrado no quadrimestre fevereiro a maio (ALVES, \& REPELLI, 1992).

O estudo de probabilidades fornece informações úteis sobre a chance de um determinado evento extremo ocorrer novamente em determinado espaço de tempo, ou seja, o período de retorno. Para a agricultura, o conhecimento dos valores normais dos elementos meteorológicos é a utilização e o conhecimento de estudos de probabilidades baseadas em eventos de chuvas intensas.

O objetivo desse trabalho é determinar as precipitações máximas para diferentes períodos de retorno através da distribuição de Gumbel, para o município de Mossoró no Rio grande do Norte.

\section{MATERIAL E MÉTODOS}

Os dados foram coletados no município de Mossoró que está situado na região semiárida do Nordeste brasileiro, no Estado do Rio Grande do Norte, localizado pelas coordenadas geográficas $5^{\circ} 11^{\prime}$ de latitude sul, $37^{\circ} 20^{\prime}$ de longitude oeste e 18 $\mathrm{m}$ de altitude, com uma temperatura média anual em torno de $27,5{ }^{\circ} \mathrm{C}$, umidade relativa de $68,9 \%$, nebulosidade média anual de 4,4 décimos e precipitação média anual de $673,9 \mathrm{~mm}$. Segundo classificação climática de Köppen, o clima de MossoróRN é do tipo BSwh', ou seja, quente e seco, tipo estepe, com estação chuvosa no verão atrasando-se para o outono (CARMO FILHO et al., 1987).

Foram utilizados dados de precipitação pluviométrica máxima anual de 1970 a 2007 (38 anos), coletados por uma estação meteorológica pertencente ao Instituto Nacional de Meteorologia, (INMET), localizada no campus da Universidade Federal Rural do Semi-Árido (UFERSA).

Os dados foram organizados por ano e posteriormente foram feitos os cálculos do período de retorno pela distribuição de Gumbel, através das séries de precipitação pluviométricas máximas utilizadas no período avaliado. Seus 
parâmetros foram encontrados por meio do método dos momentos.

A distribuição de probabilidade de Gumbel é aplicada às séries históricas de valores extremos, especialmente, a precipitação máxima diária mensal anual. Sua Função Cumulativa de Probabilidades (FCP) é representada pela Equação 1 (BERTONI, \& TUCCI, 2001).

FCP: $\mathrm{P}(\mathrm{X} \leq \mathrm{x})=\exp \left(-\exp \left(-\left(\frac{-X-\alpha}{\beta}\right)\right)\right)$

Em que $\alpha$ é o parâmetro de escala e $\beta$, o parâmetro de forma; x são os valores de precipitação máxima diária anual.

Os parâmetros são encontrados pelas equações 2 e 3 .

$$
\begin{aligned}
& \beta=\left(\frac{\sqrt{6}}{\pi}\right) . S \\
& \alpha=\bar{x}-0,5772 \cdot \beta
\end{aligned}
$$

Em que $\bar{x}$ é a média das precipitações e $\mathrm{S}$ é o desvio padrão das precipitações.

O tempo de retorno é calculado utilizando-se a Equação 4.

$$
\mathrm{TR}=\frac{1}{1-\mathrm{P}}
$$

Em que $\mathrm{P}$ é a probabilidade do evento acontecer (adimensional). TR é o tempo de retorno em anos.

A Equação 5 representa a estimativa da precipitação máxima em função dos parâmetros $\alpha$ e $\beta$, além do período de retorno.

$$
X=\beta-\operatorname{Ln}\left(-\operatorname{Ln}\left(1-\frac{1}{T R}\right)\right) \cdot \alpha
$$

\section{RESULTADOS E DISCUSSÃO}

A Tabela 1 mostra as precipitações máximas de acordo com os períodos de retorno estabelecidos.

Tabela 1 - Precipitações máximas em função do período estabelecido

\begin{tabular}{cc}
\hline Tempo de Retorno (anos) & Precipitação Máxima $(\mathrm{mm})$ \\
\hline 2 & 46.57 \\
5 & 115.43 \\
10 & 161.03 \\
20 & 204.76 \\
50 & 261.36 \\
100 & 303.78 \\
\hline
\end{tabular}

Fonte: resultados obtidos através da pesquisa.

Os resultados acima demonstrados na Tabela 1 foram encontrados através das equações já mencionadas, com ajuda do programa Excel utilizando os dados coletados na serie histórica das chuvas dos 38 anos da cidade de Mossoró. De acordo com os resultados obtidos da precipitação máxima, pode-se observar que em média a cada 2 anos é possível observar uma precipitação igual ou inferior a $46,57 \mathrm{~mm}$, sendo que esta mesma interpretação serve para os demais períodos de retorno. Em um estudo feito por meio de análise estatística de chuvas intensas na bacia hidrográfica do rio Paraíba, para um período de retorno de 100 anos das chuvas intensas de 1 dia de uma série histórica de 30 anos de precipitação fornecidas por 33 postos meteorológicos da bacia do rio Paraíba, obteve-se uma precipitação de $208,7 \mathrm{~mm}$ (ARAÚJO, 2006).

O comportamento das precipitações máximas em função do período de retorno 
estabelecido pode ser observado na Figura 1, onde observa-se um ajuste do comportamento do fenômeno mais próximo ao comportamento logaritmo.

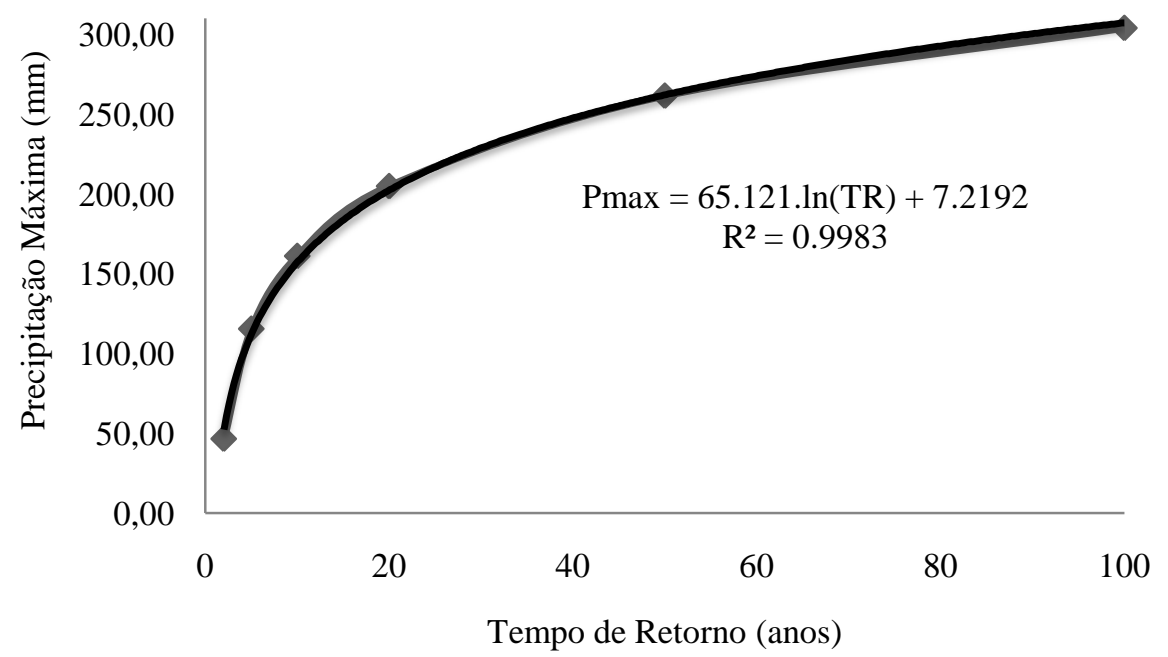

Figura 1 - Precipitação máxima em função do tempo de retorno.

\section{CONCLUSÕES}

Podemos concluir que os resultados obtidos para os tempos de retorno de 2, 5, $10, \quad 20, \quad 50$ e 100 anos foram respectivamente 46,$57 ; 115,43 ; 161,03$; 204,$76 ; 261,36$ e $303,78 \mathrm{~mm}$ para o período estudado.

Pode-se constatar que as precipitações máximas em função do tempo de retorno apresentaram um ajuste logaritmo satisfatório.

Observa-se que o método dos momentos para obtenção dos parâmetros de Gumbel pode ser encontrado de maneira mais rápida, possibilitando assim uma maior rapidez na análise dos resultados.

\section{REFERENCIAS BIBLIOGRÁFICAS}

ALVES, J. M. B.; CAMPOS, J. N. B.; NASCIMENTO, L. S. V. Sensibilidade intrasazonal de um downscaling dinâmico de precipitação (1971-2000): uma análise na bacia hidrográfica do Açude CastanhãoCe. Revista Brasileira de Meteorologia, v. 23, p. 73-87, 2008.
ALVES, J. M. B.; REPELLI, C. A: Variabilidade pluviométrica no setor norte do Nordeste e os eventos El-Niño Oscilação Sul. Revista Brasileira de Meteorologia, V.7 n. 2, 583-592. 1992.

ARAÚJO, L. E. De; Análise estatística de chuvas intensas na bacia hidrográfica do rio Paraíba. 2006. 94 f. Dissertação, (Mestrado em Meteorologia), Universidade Federal de Campina Grande (UFCG), Campina Grande.

BERTONI, J. C.; TUCCI, C. E. M. Precipitação. In: TUCCI, C. E. M. (Org.) Hidrologia: ciência e aplicação. 2. Ed. Porto Alegre: Associação Brasileira de Recursos Hídricos/Editora Universidade Federal do Rio Grande do Sul, 2001. p. 177-242.

CARMO FILHO, F.; ESPÍNOLA SOBRINHO, J.; AMORIM, A. P. Dados meteorológicos de Mossoró (janeiro de 1898 a dezembro de 1986). Mossoró: ESAM/FGD, 1987. v. 341, 325p.

MARENGO, J, A; ALVES, L; VALVERDE, M; ROCHA, R; 
LABORDE, R, 2007: Eventos extremos em cenários regionalizados de clima no Brasil e América do Sul para o Século XXI: Projeções de clima futuro usando três modelos regionais. Relatório 5,

MINISTÉRIO DO MEIO AMBIENTE MMA, SECRETARIA DE BIODIVERSIDADE E FLORESTAS SBF, DIRETORIA DE CONSERVAÇÃO DA BIODIVERSIDADE - DCBio Mudanças Climáticas Globais e Efeitos sobre a Biodiversidade - Sub projeto: Caracterização do clima atual e definição das alterações climáticas para o território brasileiro ao longo do Século XXI. Brasília, Fevereiro 2007.

ORTOLANI, A. A.; CAMARGO, M. B. P. Influência dos fatores climáticos na produção. Ecofisiologia da Produção Agrícola. Piracicaba: Potafos, 249 p., 1987.
SANTANA, M. O. SEDIYAMA, G. C., RIBEIRO, A., SILVA, D. D. da. Caracterização da estação chuvosa para o estado de Minas Gerais. Revista Brasileira de Agrometeorologia, v.15, n.1, p.114-120, 2007.

SANTOS, W. O. Ajuste da evapotranspiração de referência estimada através de 10 métodos em Mossoró-RN à diferentes distribuições densidade de probabilidade. 2010. $222 \mathrm{f}$. Monografia (Graduação em Agronomia)Universidade Federal Rural do Semi Árido (UFERSA), Mossoró.

TUCCI, C.E.M. 2000. Hidrologia Ciência e Aplicação. Porto Alegre: UFRGS, 2000. 943p. 